\title{
Management of abnormal uterine bleeding - focus on ambulatory hysteroscopy
}

This article was published in the following Dove Press journal: International Journal of Women's Health

\author{
Shilpa Kolhe \\ Ambulatory Gynaecology Unit, Royal \\ Derby Hospital, Derby, UK
}

\begin{abstract}
The rapid evolution in ambulatory hysteroscopy $(\mathrm{AH})$ has transformed the approach to diagnose and manage abnormal uterine bleeding (AUB). The medical management in primary care remains the mainstay for initial treatment of this common presentation; however, many women are referred to secondary care for further evaluation. To confirm the diagnosis of suspected intrauterine pathology, the traditional diagnostic tool of day case hysteroscopy and dilatation and curettage in a hospital setting under general anesthesia is now no longer required. The combination of ultrasound diagnostics and modern AH now allows thorough evaluation of uterine cavity in an outpatient setting. Advent of miniature hysteroscopic operative systems has revolutionized the ways in which clinicians can not only diagnose but also treat menstrual disorders such as heavy menstrual bleeding, intermenstrual bleeding and postmenopausal bleeding in most women predominantly in a one-stop clinic. This review discussed the approach to manage women presenting with AUB with a focus on the role of $\mathrm{AH}$ in the diagnosis and treatment of this common condition in an outpatient setting.
\end{abstract}

Keywords: abnormal uterine bleeding, ambulatory hysteroscopy, endometrial polyps, one-stop clinic, vaginoscopic approach

\section{Introduction}

Abnormal uterine bleeding (AUB) is very common in women of every age group from adolescence to menopause and includes heavy menstrual bleeding (HMB), irregular or intermenstrual bleeding (IMB) and postmenopausal bleeding (PMB). In particular, PMB and persistent IMB are known as red flag symptoms of suspected endometrial cancer and cervical cancer. Every year, 30,000 women undergo surgical treatment for HMB in England and Wales. ${ }^{1}$ Recent organizational survey in the UK revealed that over half of the hospitals indicated changes in the management of HMB in primary care, with the introduction of new care pathways and a higher proportion of women than before receiving some kind of initial treatment in primary care. ${ }^{1}$

A large proportion of women are still referred to secondary care facility for diagnosis and management of various menstrual disorders. The easy accessibility of diagnostic tools such as pelvic ultrasound, endometrial sampling and, most importantly, the facilities to perform outpatient hysteroscopy has made it possible to promptly diagnose and treat an increasing number of menstrual disorders in an office setting. Conventional day case hysteroscopy and dilatation of the cervix and curettage of the endometrium (D\&C) is now rarely necessary. Advances in technology have led to miniaturization of high-definition hysteroscopes without compromising optical performance, thereby making hysteroscopy a simple, safe and well-tolerated office procedure. Ambulatory hysteroscopy (AH) allows an efficient and accurate diagnosis of intrauterine pathology, 
including submucous fibroids, endometrial polyps and potentially hyperplasia and cancer. ${ }^{2,3}$ In addition to diagnosis, it also enables appropriately skilled gynecologist to institute minimally invasive therapeutic interventions to treat the diagnosed pathology simultaneously. There is good evidence to suggest that hysteroscopy in an ambulatory setting is preferred by most women, avoids complications and allows a quicker recovery time.,

This article reviewed the management of AUB with focus on $\mathrm{AH}$ and its role in the workup and treatment of women presenting to secondary care with AUB.

\section{AUB}

AUB affects women of all ages and constitutes a major proportion of outpatient referrals to the department of gynecology. The lifetime prevalence of AUB in women is 30\%. AUB can have a significant impact on women's quality of life. Most women present with HMB that affects their medical, social, economic and psychological well-being. ${ }^{5}$ The International Federation of Gynecology and Obstetrics (FIGO) classification system for causes of AUB (PALM-COEIN) provides an excellent framework to approach the management of this condition in nongravid reproductive-age women. ${ }^{6}$ The structural anomalies responsible for causing abnormal bleeding are classified as PALM: polyp, adenomyosis, leiomyoma and malignancy/ hyperplasia. The other categories causing abnormal bleeding that are unrelated to structural anomalies are classified as COEIN: coagulopathy, ovulatory dysfunction, endometrial, iatrogenic and not yet classified $(\mathrm{N})$ category (Figure 1).

Multiple factors can contribute to the genesis of AUB, and this may vary depending on the age of the woman and the symptoms at presentation. Often there may be pathology (eg, subserosal fibroid) that is present but not thought to be contributing to AUB. Therefore, the investigation of women with AUB must be undertaken diligently in a comprehensive manner, ensuring appropriate use of the available resources.

\section{Differential diagnosis for AUB}

A thorough history with focus on abnormal bleeding pattern and the possible causes of these symptoms in the specific age group should guide the clinician to determine the course of investigations to take in women with AUB. Table 1 summarizes the differential diagnoses in various age groups that can present with AUB.

Initial evaluation and general clinical assessment along with the severity of presenting symptoms will further indicate whether to proceed with relevant laboratory investigations, imaging and/or histology. Histology is not often warranted in younger women presenting with menstrual disorders.

\section{Prepubertal girls}

The causes of vaginal bleeding in young premenarchal girls differ substantially from those in postpubertal girls. Most commonly, it is secondary to bleeding from the lower genital tract (vulvovaginitis, foreign body, trauma, urethral prolapse) rather than uterine origin. Bright red spotting should alert the clinician about the possibility of malignant lesions in the lower genital tract such as sarcoma botryoides or endodermal sinus tumor of the vagina. Other cause of uterine bleeding in this age group is attributed to precocious puberty, which may have hormone-producing ovarian tumor as an underlying cause.

The approach to evaluation of AUB in this age group should therefore reflect relevant investigations directed at abovementioned differential diagnoses.

\section{Postmenarchal/adolescent girls}

The most common cause of AUB in adolescents is anovulation. Anovulatory uterine bleeding generally resolves with maturation of the hypothalamic-pituitary-ovarian axis. Approximately $85 \%$ of menstrual cycles are anovulatory in the first year after menarche, and $56 \%$ of menstrual cycles are ovulatory 4 years after menarche. Within the PALM-COEIN classification of AUB, the structural causes (polyps, fibroids, adenomyosis) are rare in adolescents.

Some common causes include bleeding disorders, polycystic ovarian syndrome (PCOS), endocrine dysfunction, stress, hormonal/contraception/pregnancy-related problems and infection. It is estimated that $36 \%-44 \%$ of adolescents with HMB have von Willebrand disease or platelet

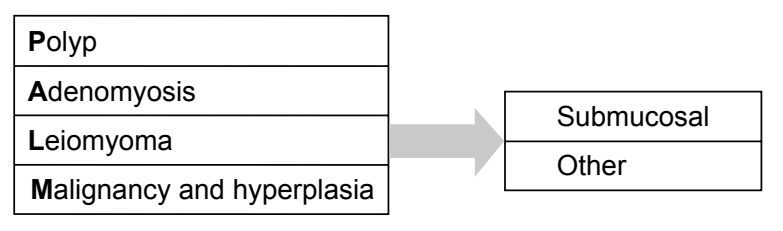

Figure I FIGO classification of PALM-COEIN system.

Abbreviation: FIGO, International Federation of Gynecology and Obstetrics.

\begin{tabular}{|l|}
\hline Coagulopathy \\
\hline Ovulatory dysfunction \\
\hline Endometrial \\
\hline Iatrogenic \\
\hline Not yet classified \\
\hline
\end{tabular}


Table I Differential diagnosis of AUB according to age groups

\begin{tabular}{l} 
Neonate \\
Estrogen withdrawal \\
Prepubertal \\
Foreign body \\
Trauma, sexual abuse \\
Infection - vulvovaginitis \\
Urethral prolapse \\
Precocious puberty \\
Ovarian/vaginal tumor \\
Postmenarchal \\
Anovulation \\
Bleeding disorders \\
Pregnancy \\
Infection - PID \\
PCOS \\
Reproductive age group \\
Anovulation \\
Pregnancy \\
Polyps, adenomyosis, fibroids \\
Cancer \\
Infection \\
Endocrine disorders (PCOS, thyroid disorders, pituitary adenoma) \\
Bleeding disorders \\
latrogenic: OCP/IUD/antipsychotic \\
Perimenopausal \\
Anovulation \\
Polyps, adenomyosis, fibroids \\
Cancer \\
Menopausal \\
Atrophy \\
Cancer \\
Polyp \\
latrogenic (ERT, HRT, IUD, steroid injections, tamoxifen) \\
\hline Abbrevions: AUB, abro \\
\hline
\end{tabular}

Abbreviations: AUB, abnormal uterine bleeding; PID, pelvic inflammatory disease; PCOS, polycystic ovarian syndrome; OCP, oral contraceptive pills; IUD, intrauterine device; ERT, estrogen replacement therapy; HRT, hormone replacement therapy.

dysfunction. ${ }^{7}$ A simple screening tool as shown in Table $2^{6}$ can be used as a guide. Girls and older women with positive screening warrant further hematological investigations, including testing for von Willebrand factor and Ristocetin factor and consultation with a hematologist. Other bleeding disorders include Factor XI deficiency or hemophilia carrier states.

\section{Reproductive age women}

Majority of women presenting with AUB belong to this age group. These women are more likely to have the structural abnormalities such as endometrial polyps (AUB-P) or fibroids (AUB-L) and are equally likely to have ovulatory dysfunction (AUB-O) and primary disorder of endometrium (AUB-E) as described within the PALM-COEIN classification system. History taking should take into account the range and natural variability in menstrual cycles and blood loss when diagnosing HMB. It is acceptable to commence pharmaceutical
Table 2 Clinical screening for an underlying hemostatic disorder in women presenting with excessive menstrual bleeding

\begin{tabular}{l} 
Positive screening comprises any of the following elicited by a \\
structured history \\
\hline HMB since menarche \\
One of the following: \\
Postpartum hemorrhage \\
Surgery related bleeding \\
Dental procedure-related bleeding \\
Two or more of the following: \\
Bruising one to two times per month \\
Epistaxis one to two times per month \\
Frequent gum bleeding \\
Family history of bleeding symptoms
\end{tabular}

Abbreviation: $\mathrm{HMB}$, heavy menstrual bleeding.

treatment without other investigations at initial consultation in primary care (National Institute of Clinical Excellence 2007 [NICE]). Physical examination including speculum examination and a bimanual examination is recommended to evaluate the lower genital tract and pelvis to confirm the source of bleeding and to look for structural causes such as fibroids or cervical polyps. Ultrasound assessment may be requested if clinical history or examination warrants further information such as persistent IMB, prolonged periods of bleeding and clinical finding of fibroid uterus.

Further investigations such as endometrial biopsy (EB) and hysteroscopic assessment of uterine cavity are not routinely required to investigate AUB, especially in the younger women. These can be associated with significant discomfort and should be used diligently when necessary in women who have failed to respond to initial medical therapy or in those with risk factors for endometrial malignancy (Figure 2).

\section{Perimenopausal and postmenopausal women}

For women in this age group presenting with new onset AUB, organic pathology, particularly for atypical hyperplasia or endometrial cancer, must be ruled out as anovulatory cycles and organic pathology can coexist, especially in the perimenopausal women. In postmenopausal women, the high incidence of endometrial polyps is well studied. ${ }^{8-12}$ In a study, $23 \%$ of benign endometrial polyps and $100 \%$ of malignant ones presented with symptoms of PMB. ${ }^{8}$

NICE (2007) recommended ultrasound as the first-line screening tool for identifying structural abnormalities. ${ }^{13}$ Hysteroscopy remains the gold standard for accurate assessment of endometrium. Indications for EB for histological assessment include women aged $\geq 45$ years, treatment failure, ineffective treatment, persistent IMB and presence of risk factors (Figure 2). 


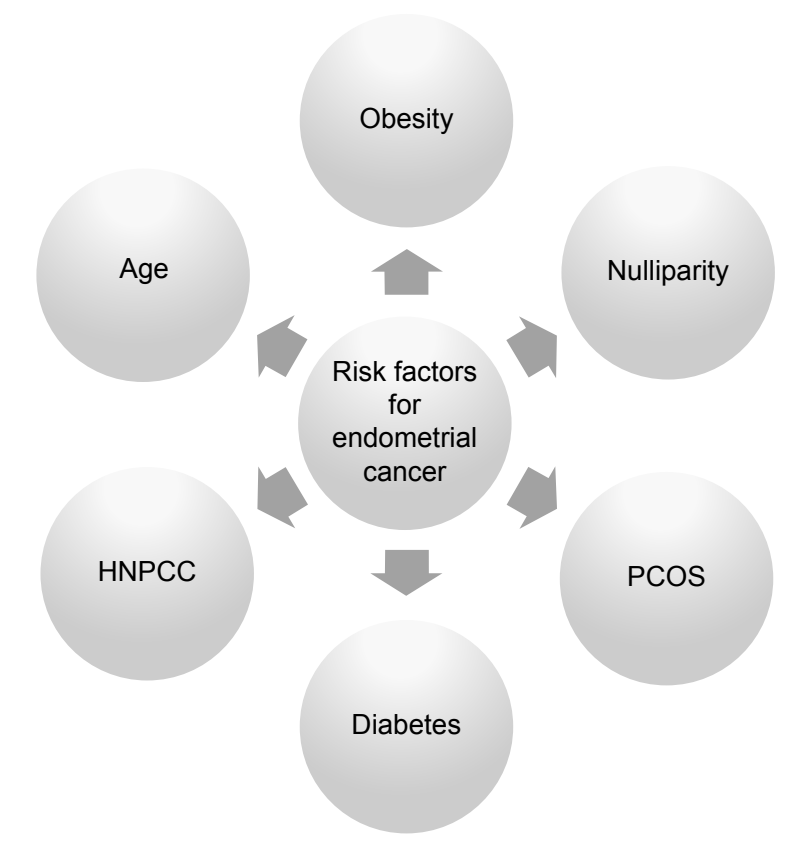

Figure 2 Risk factors for endometrial cancer.

Abbreviations: PCOS, polycystic ovarian syndrome; HNPCC, hereditary nonpolyposis colorectal cancer.

As PMB warrants thorough investigation to rule out endometrial cancer, it is one of the triggers to initiate an urgent referral pathway. One-stop clinics as discussed later in this review are best suited for this group of women.

\section{Role of AH in diagnosis of AUB}

The role of hysteroscopy is instrumental in evaluating the uterine cavity in women with abnormal bleeding and has been the gold standard for several years. In the UK, there is national best practice recommendation that all gynecology units should provide dedicated outpatient hysteroscopy service to aid management of women with AUB. The developments in AH have further fueled the use of this diagnostic modality, and it is no longer necessary to subject women requiring hysteroscopy to a general anesthetic. In majority of women, the diagnosis for AUB disorders can be offered in an ambulatory setting using a one-stop approach with a combination of various ambulatory tests, including blood tests, ultrasonography, outpatient hysteroscopy and EB.

In the UK, the ambulatory diagnostic hysteroscopy services are well established in most NHS hospitals, but there is still some inconsistency regarding the provision of see-and-treat one-stop clinics for AUB. Most hospitals do have one-stop clinics setup for women presenting with postmenopausal bleeding, but this efficient one-stop service is not yet widely available for women presenting with HMB due to variations in management pathways.
Since the publication of the green top guideline on best practice in outpatient hysteroscopy by the Royal College of Obstetricians and Gynaecologists in $2011^{14}$ there is an increasing trend nationally toward offering ambulatory hysteroscopic procedures and optimizing patient experience with particular interest in pain control during these procedures. As with any procedure requiring instrumentation of the uterus, outpatient hysteroscopy can be associated with significant pain. ${ }^{15,16}$ So invasive test such as this should only be undertaken if it would help influence the management plan, such as in women with PMB with increased endometrial thickness, premenopausal AUB in those who have suspected intracavitary abnormality on ultrasound or clinical symptoms such as persistent IMB. A single episode of AUB in premenopausal woman or a one-off episode of IMB in a young woman does not warrant hysteroscopy in contrast to persistent abnormal bleeding for several months or prolonged continuous heavy bleeding.

\section{Initial investigations}

Detailed history and clinical evaluation of the presenting symptoms should guide further management. There are pathways that can be used effectively for management of various forms of AUB, and these are generally useful for primary care professionals. An example of one such pathway (Figure 3) is the pathway developed by Gynaecology Clinical Improvement Group in South Derbyshire for initial evaluation of HMB before considering secondary care referral. The diagnostic options are different in postmenopausal and premenopausal women. Since the main issue in postmenopausal women is to exclude hyperplasia and malignancy, these women should have a fast-track diagnostic setup with a one-stop see-and-treat service.

This review considered management of AUB in secondary care, where each case is best individualized based on woman's age, duration and severity of her symptoms and differential diagnoses based on the doctor's judgment as to the underlying cause of bleeding. In general, invasive investigations should be performed only if they will make a material difference to the management approaches that can be offered. ${ }^{17}$

Initial laboratory evaluation with a simple full blood count is practical in most cases and should rule out anemia as a consequence of abnormal bleeding pattern, especially if longstanding or severe symptoms exist. Other blood tests such as thyroid function tests, screening for clotting or bleeding disorders and hormonal profile to determine ovulatory status should be instigated if necessary based on the differential diagnoses considered after a thorough clinical history. 


\section{Derby hospitals WHS \\ NHS foundation trust \\ WHS \\ Southern derbyshire clinical commissioning group}

Risk factors for endometrial cancer: PCOS, obesity, diabetes, nulliparity, late menopause, unopposed oestrogen therapy, functioning ovarian tumors, previous pelvic irradiation, family history of cancer of breast ovary or colon, women on tamoxifen, hypertension, history of endometrial hyperplasia

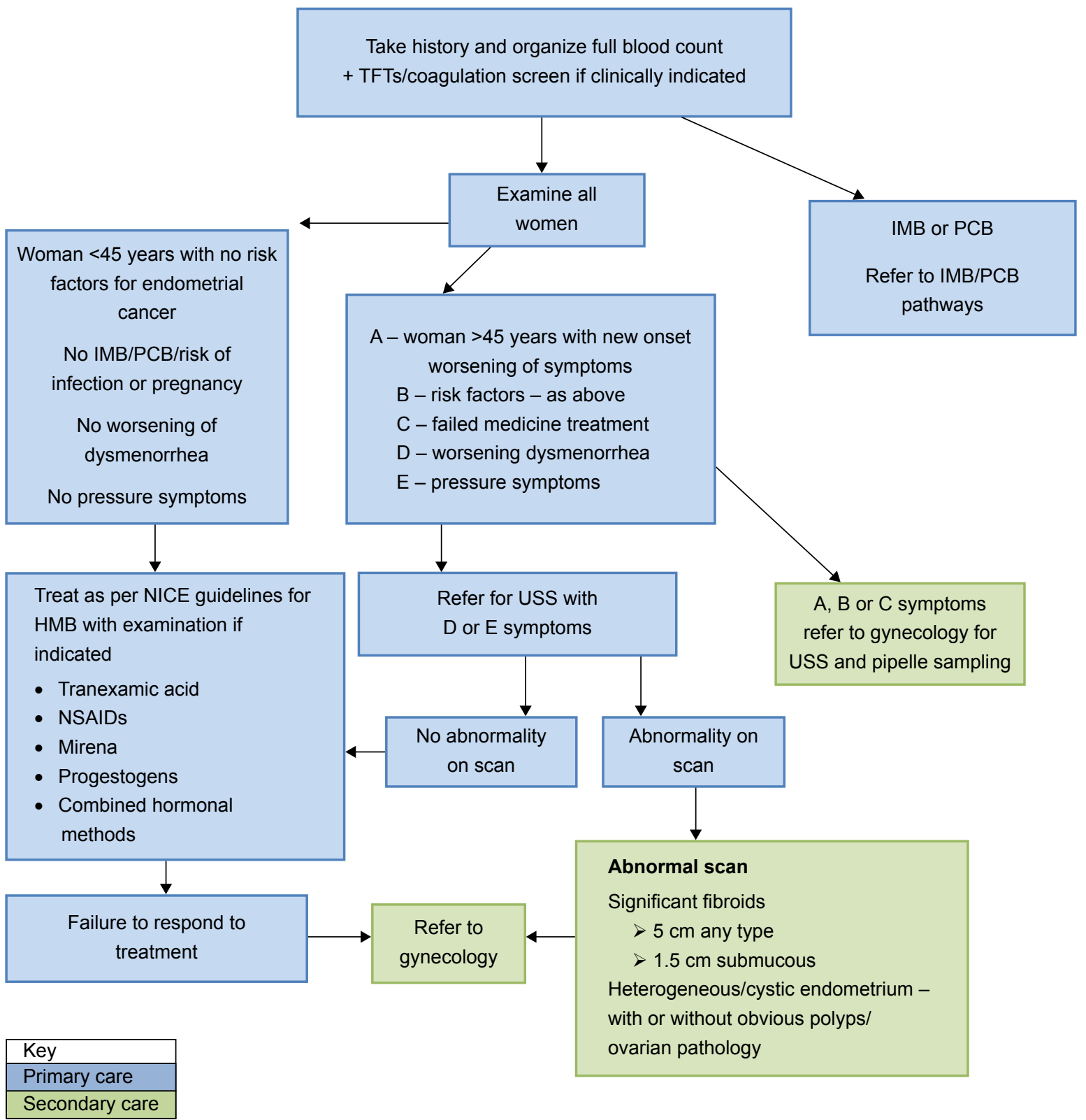

Figure 3 Example pathway for $\mathrm{HMB}$

Abbreviations: HMB, heavy menstrual bleeding; IMB, intermenstrual bleeding; NSAID, nonsteroidal anti-inflammatory drug; PCOS, polycystic ovarian syndrome; NHS, National Health Service; NICE, National Institute of Clinical Excellence; TFT, thyroid function test; PCB, postcoital bleeding; USS, ultrasound sscan.

Furthermore, one should also consider a pregnancy test to rule out unexpected pregnancy-related bleeding, vaginal swabs to rule out possible pelvic infection and cervical smear if indicated.

\section{Specific investigations}

Specific diagnostic investigations include tests for further evaluation of the uterine or endometrial causes of AUB such as polyps, adenomyosis, fibroids, endometrial hyperplasia 
or malignancy (PALM). There are several tests that can be used with variable accuracy to detect these structural abnormalities, including pelvic imaging, endometrial sampling and hysteroscopy. These should be combined and perceived as complementary methods for optimal evaluation of the uterine cavity.

\section{Pelvic imaging}

Transvaginal ultrasonography (TVS) is an appropriate firstline screening tool for women with AUB as it is inexpensive, noninvasive and easily accessible. It should be performed early in the course of investigations of chronic AUB in women of reproductive age group and even sooner in those women with postmenopausal bleeding. The benefits and diagnostic effectiveness of TVS in assessing the uterus, unlike hysteroscopy, extend to the complete pelvis. ${ }^{18}$ TVS is the most convenient way to visualize the endometrial cavity and has an added advantage of assessing uterine myometrium as well as ovarian and adnexal pathology at the same time. Emanuel et a ${ }^{19}$ demonstrated TVS to have a sensitivity of 0.96 and a specificity of 0.89 .

However, even with good quality ultrasound equipment in ideal circumstances, TVS is not $100 \%$ sensitive because polyps and other focal lesions may elude detection..$^{20,21}$ It can give false-positive results especially when done in secretory phase of the menstrual cycle. In addition, where vaginal access is difficult, as with adolescents and virginal women, TVS is not appropriate and transabdominal pelvic ultrasound with a full bladder can be used. Alternatively, role of MRI or hysteroscopy under anesthesia may be considered occasionally to investigate chronic AUB in this group of patients if medical management has failed to improve symptoms.

\section{Other imaging modalities}

1. Contrast hysterosonography $(\mathrm{COH})$ with saline infusion sonography (SIS): the accuracy of TVS in diagnosing intracavity pathology such as submucous fibroids and polyps is improved with SIS to levels of accuracy comparable to that of outpatient hysteroscopy. ${ }^{22-24}$ SIS improves efficacy of TVS in evaluating endometrial cavity. ${ }^{25}$ However, its benefit is offset by the invasive nature of this scan, although one can argue that it is less invasive than hysteroscopy. ${ }^{26}$

2. Magnetic resonance imaging: MRI is more accurate than TVS in the presence of multiple fibroids to allow mapping and instigate appropriate treatment in selective cases. ${ }^{27}$ This is an expensive test and is not routinely used unless for cases of endometrial cancer to facilitate staging.

\section{Endometrial sampling}

EB is not required for all patients with AUB. Doctors should use their clinical acumen and assessment of risk factors in order to determine which group of patients would benefit from histological evaluation of endometrium.

There are several techniques available to obtain a sample for histology, including simple aspiration (pipelle biopsy), blind D\&C and more recently, directed hysteroscopic biopsies in an outpatient setting.

The historical procedure of $\mathrm{D} \& \mathrm{C}$ of endometrium has now become obsolete and is no longer acceptable as the standard of care for endometrial assessment unless it is used concomitantly with hysteroscopy. Bettocchi et $\mathrm{al}^{28}$ found that $>50 \%$ of intrauterine lesions were missed when a D\&C was performed alone.

The 1980s ushered in the pipelle EB device for outpatient sampling of the endometrium in women with AUB. It is a small-diameter, disposable, flexible cannula that can be used to perform a biopsy quickly in a clinic during speculum examination and is reasonably tolerated. Two meta-analyses have clearly emphasized the satisfactory sensitivity and specificity of an EB in the diagnosis of endometrial cancer in women with AUB. ${ }^{3,29}$ However, this is true when there is global endometrial pathology, and blind pipelle biopsy can be falsely negative in women with focal lesions. A positive test result of EB is more accurate for ruling in disease than a negative test result is for ruling it out. Therefore, in cases of AUB where symptoms persist despite negative biopsy, further evaluation is warranted. ${ }^{3}$

Particularly in premenopausal women, endometrial sampling is not efficient for the diagnosis of endometrial polyps, adenomyosis or fibroids. Focal endometrial abnormalities are frequent causes of AUB in postmenopausal women, and although most of these lesions are benign, it is important to diagnose and treat them to resolve the presenting symptoms and rule out malignancy. This is best achieved by hysteroscopy and removal of the focal lesion under direct vision.

\section{$\mathrm{AH}$}

Hysteroscopy is confirmed as the gold standard in the assessment of AUB in menopause, permitting the elimination of the false-negative results of blind biopsy through direct visualization of the uterine cavity and the performance of targeted biopsy in case of doubt. ${ }^{30}$ It permits full visualization of the endocervix, endometrial cavity and tubal ostia, allowing visual diagnosis of focal endometrial lesions that are missed with endometrial sampling, TVS or SIS..$^{24}$ In addition, vaginoscopic approach to perform $\mathrm{AH}$ can also be used for careful 
Table 3 Statistical results of hysteroscopy in the diagnosis of benign pathology

\begin{tabular}{llll}
\hline Hysteroscopy & Polyps & Myomas & Hyperplasia \\
\hline Sensitivity, \% (95\% Cl) & $89(82-93)$ & $100(68-100)$ & $74(62-84)$ \\
Specificity, \% (95\% Cl) & $93(88-96)$ & $99(98-100)$ & $93(89-95)$ \\
Accuracy, \% & 91 & 99 & 90 \\
PPV, \% & 90 & 80 & 70 \\
NPV, \% & 92 & 100 & 94 \\
\hline
\end{tabular}

Note: Data from Angioni et al..$^{30}$

Abbreviations: PPV, positive predictive value; NPV, negative predictive value.

evaluation of any vaginal pathology that may be a culprit for AUB. ${ }^{31}$ Besides, this approach reduces discomfort in all patients, including those with moderate stenosis of the internal cervical os and can be successfully used in virginal older women who otherwise would need general anesthetic. The high accuracy, sensitivity and specificity of hysteroscopy are well studied (Table 3). ${ }^{30,32,33}$ With miniaturization of hysteroscopes and newer treatment modalities such as bipolar devices and hysteroscopic morcellators, outpatient hysteroscopy is no longer just a simple diagnostic test but can offer "see-andtreat" approach to these women presenting with AUB.

$\mathrm{AH}$ has been widely recommended with substantial evidence to prove its safety, efficacy and acceptability, but it is a mini-invasive procedure and can be associated with complications including severe pain. ${ }^{34,35}$ Although major complications are extremely rare. ${ }^{36-39}$ Hysteroscopy may be unnecessary when a normal endometrial cavity has been optimally visualized using simple TVS or $\mathrm{COH}$. Like other methods, hysteroscopy is also beset by limitations, especially in premenopausal women. Some of these include phase of the menstrual cycle, presence of copious bleeding and mistaking uneven surfaces as pathologic. Excessive uterine distension can affect the detection of disease..$^{40}$ There are several studies regarding the accuracy of ultrasound and hysteroscopy in the diagnosis of endometrial disease. ${ }^{41,42}$

Cooper et al ${ }^{43}$ published an analysis of cost-effectiveness of different strategies for investigating AUB and concluded that outpatient hysteroscopy appeared to be the most cost-effective first-line investigation for women with HMB referred to secondary care after failed medical interventions, including levonorgestrel intrauterine system (LNG-IUS). In conclusion, the above investigations should be used to complement each other depending on available resources to achieve an accurate diagnosis that would then help the clinician to optimize the management of women presenting with AUB.

\section{AH and treatment of AUB}

After excluding malignancy, the treatment goals for management of women with AUB include reduction of blood loss, improvement in quality of life and the treatment of any structural abnormality that appears to be contributing to the AUB. Pharmacological treatment for regulation of the menstrual cycles and reduction of monthly bleeding should ideally be the first-line treatment offered in primary care prior to considering referral of these women with AUB to secondary care. This involves the non-hormonal and hormonal treatment options, including the LNG-IUS, in suitable cases.

$\mathrm{AH}$ is instrumental in the management of AUB (HMB, IMB and PMB), particularly when structural pathologies diagnosed by $\mathrm{AH}$ are suitable for immediate treatment as a one-stop see-and-treat approach.

\section{$\mathrm{AH}$ and treatment of AUB-P}

Endometrial polyps are diagnosed in $20 \%-40 \%$ of women with AUB. ${ }^{33}$ There is a paucity of quality literature assessing the efficacy and rationale for surgical intervention to remove polyps associated with AUB. ${ }^{44}$ The available evidence supports the current practice of hysteroscopic polypectomy to alleviate the symptoms of AUB in premenopausal women. ${ }^{45}$ Nobody would argue over this management in postmenopausal women with bleeding due to the small association with malignant potential in polyps; however, there is no national consensus guidance on the management of asymptomatic polyps incidentally found in postmenopausal women.

It is now a standard practice in most NHS hospitals to offer outpatient treatment of endometrial polyps. With advances in endoscopic technology, it is now possible to offer therapeutic ambulatory hysteroscopic procedures without the need for hospital admission and anesthesia. ${ }^{46,47}$ Outpatient Polyp Treatment trial showed outpatient polypectomy was noninferior to inpatient polypectomy in alleviating AUB and was an overall safe, feasible and acceptable procedure. ${ }^{48}$ There are various different mechanical and electrosurgical techniques that can be used to perform endometrial polypectomy in an outpatient setting. ${ }^{49,50}$ These include fine scissors and grasping forceps (ideally suited for small solitary lateral wall polyps), bipolar electrodes for rapid cutting of larger polyps followed by graspers/polyp snares to retrieve the specimen and more recently, hysteroscopic morcellators with inbuilt tissue retrieval systems (best suited for large/fundal/multiple polyps). Outpatient polypectomy has been shown to be more cost-effective than inpatient polypectomy. ${ }^{51}$ This is best achieved by the morcellators that allow quicker, less painful and more complete retrieval of the lesion (Figure 4). ${ }^{52}$

The convenience and immediacy of the see-and-treat approach seem to be advantageous, especially in the onestop setup ideal for urgent referrals for women with PMB. 


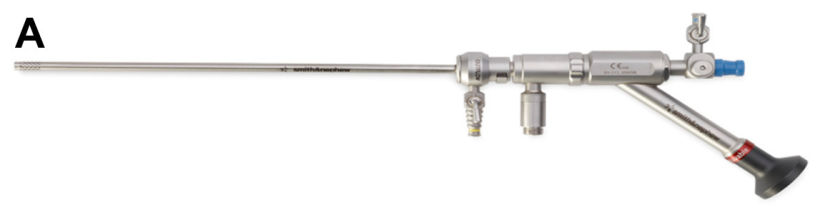

B

Figure 4 TRUCLEAR ${ }^{\mathrm{TM}}$ Operative Hysteroscope $5.0(\mathbf{A})$ and the morcellator device 2.9 (B).

Note: Reprinted from Best Practices Res Clin Obstet Gynaecology, 7, Kolhe S, Setting up of ambulatory hysteroscopy service, 966-981, Copyright (20I5), with permission from Elsevier. ${ }^{60}$

To increase acceptability of this new approach, it is extremely crucial that women attending one-stop clinics are well informed. Appropriate patient information leaflets for TVS and outpatient hysteroscopy should be posted along with the appointment letter to all women due to attend these clinics. Pain relief should be offered to all patients undergoing outpatient polypectomy to improve patient satisfaction and tolerance. Most patients tolerate ambulatory hysteroscopic procedures extremely well, especially with vaginoscopic approach without use of speculum and tenaculum. All patients undergoing ambulatory hysteroscopic procedures should sign a written consent form with thorough counseling of risks associated, including pain, bleeding, infection, uterine perforation and trauma to adjacent organs, although these are rarely encountered in an ambulatory setup.

\section{$\mathrm{AH}$ and treatment of AUB-E}

AH can be justified in those women with HMB who have failed to respond to initial hormonal/medical treatment. The concomitant use of $\mathrm{AH}$ can be considered at the time of fitting LNG-IUS in selected difficult cases, for example, cervical stenosis secondary to previous cone biopsy, previous caesarean sections with pin-point cervical os, acutely anteverted/ retroverted cavity, fibroid uterus with distorted cavity and extreme obesity limiting access to lower genital tract.

In those women who have completed child bearing and had ineffective/undesired medical management or LNG-IUS for AUB-E, the second-line treatment offered should be endometrial ablation. AH and EB allow pre-ablation assessment of the endometrial cavity and rule out any structural abnormality as well as exclude atypical hyperplasia prior to offering ablation treatment. They also give an idea whether or not the woman might be suitable for the ablation treatment in an ambulatory setting. In my experience, if the woman coped well with the pipelle biopsy and/or diagnostic hysteroscopy, then she can be offered a choice of outpatient ablation treatment with appropriate preoperative analgesia and counselling.
There are several endometrial ablation devices available for use in an outpatient setting: thermablate balloon ablation with a treatment cycle of 2 minutes and 30 seconds,${ }^{53}$ radiofrequency impedance-controlled ablation (NovaSure/NovaSure ADVANCED) with a treatment cycle of 90 seconds $^{54}$ and newer ablation devices such as Minitouch thermal ablation with a treatment cycle of $60-90$ seconds $^{55}$ and Librata disposable balloon ablation device with treatment cycle of 2 minutes. Hysteroscopic examination immediately before ablation is recommended to ensure absence of any endometrial lesion and to exclude any false passage prior to insertion of the ablation device. In terms of efficacy of the various ablation techniques, the improvement in bleeding and patient satisfaction, there is no evidence of any significant difference. ${ }^{56,57}$ Shorter treatment duration favors successful completion of the procedure in an ambulatory setting.

\section{$\mathrm{AH}$ and $\mathrm{AUB}$-leiomyoma/fibroid}

Submucosal fibroids are most likely to contribute to the genesis of AUB. Subclassification of fibroids to categorize submucosal location to type 0,1 or 2 is particularly relevant for the clinician to select appropriate cases for hysteroscopic myomectomy. AH allows most accurate diagnosis of submucous fibroid and so enables more the surgeon to plan the best way to treat them surgically. Smaller grade 0 submucous fibroids can be removed in the outpatient setting. ${ }^{58} \mathrm{Few}$ practitioners advocate using traditional monopolar resectoscopes in an outpatient setting; however, in general, most prefer to use the safer bipolar electrosurgery or morcellators with specially designed blades to cut through the fibrous tissue. Those submucous fibroids $>3 \mathrm{~cm}$ and those requiring preoperative downregulation with gonadotropin-releasing hormone analogs or ulipristal acetate are best operated upon in the conventional operating theatre with general or regional anesthesia as appropriate.

\section{$\mathrm{AH}$ and $\mathrm{AUB}$-malignancy/hyperplasia}

$\mathrm{AH}$ is the most effective way to shorten the referral to treatment pathway for women referred on an urgent cancer pathway to rule out endometrial malignancy. The general practitioners should have access to "one-stop see-and-treat" AH clinics designed for women with PMB.

As discussed earlier, various ambulatory techniques can be used to treat polyps or focal suspicious endometrial lesions diagnosed during $\mathrm{AH}$, and in most cases, this can be successfully achieved as a part of the same procedure. The gynecologist should discern the importance of complete retrieval of polyps, especially when performing this 
procedure in postmenopausal women to avoid the risk of false-negative biopsies obtained from polyps and the possibility of finding a focus of endometrial cancer involving the stalk of the polyp. ${ }^{59}$

\section{Conclusion}

AH has evolved from strength to strength over the last few decades. It is acceptable to most women to have ambulatory hysteroscopic treatment of their distressing symptoms of AUB, thereby making it an attractive to most NHS trusts to offer this service due to its cost-effectiveness. Recent technological advances have led to introduction of portable all-in-one hand-held battery-operated flexible diagnostic hysteroscope (Endosee) and the portable rigid mini hysteroscopes (diagnostic and therapeutic) with cordless light source and camera (LiteOptics) that offer a perfect balance between patient comfort and image quality in an ambulatory setup. These advances have opened up new avenues for community services. AH is ideal to manage AUB, and the next step would be to offer these services in the community setting closer to home. Portable hysteroscopes can be used to select and treat straightforward cases in the community and triage the complex ones to secondary care ambulatory set up, thereby reducing referrals. This will enable more efficient utilization of the resources in secondary care.

\section{Disclosure}

The author reports no conflicts of interest in this work.

\section{References}

1. RCOG. National Heavy Menstrual Bleeding Audit, UK Final Report. 2014.

2. Bakour SH, Jones SE, O'Donovan P. Ambulatory hysteroscopy: evidence-based guide to diagnosis and therapy. Best Pract Res Clin Obstet Gynaecol. 2006;20(6):953-975.

3. Clark TJ, Mann CH, Shah N, Khan KS, Song F, Gupta JK. Accuracy of outpatient endometrial biopsy in the diagnosis of endometrial cancer: a systematic quantitative review. BJOG. 2002;109(3):313-321.

4. Marsh F, Kremer C, Duffy S. Delivering an effective outpatient service in gynaecology. A randomised controlled trial analysing the cost of outpatient versus daycase hysteroscopy. BJOG. 2004;111(3):243-248.

5. Gath D, Osborn M, Bungay G, et al. Psychiatric disorder and gynaecological symptoms in middle aged women: a community survey. $\mathrm{Br} \mathrm{Med} J$ (Clin Res Ed). 1987;294(6566):213-218.

6. Munro MG, Critchley HO, Broder MS, Fraser IS; FIGO Working Group on Menstrual Disorders. FIGO classification system (PALM-COEIN) for causes of abnormal uterine bleeding in nongravid women of reproductive age. Int J Gynaecol Obstet. 2011;113(1):3-13.

7. James AH. Bleeding disorders in adolescents. Obstet Gynecol Clin North Am. 2009;36(1):153-162.

8. Miranda SM, Gomes MT, Silva ID, Girao MJ. Pólipos endometriais: aspectos clínicos, epidemiológicos e pesquisa de polimorfismos [Endometrial polyps: clinical and epidemiological aspects and analysis of polymorphisms]. Rev Bras Ginecol Obstet. 2010;32(7):327-333. Portuguese.

9. Biron-Shental T, Tepper R, Fishman A, Shapira J, Cohen I. Recurrent endometrial polyps in postmenopausal breast cancer patients on tamoxifen. Gynecol Oncol. 2003;90(2):382-386.
10. Perez-Medina T, Bajo-Arenas J, Haya J, et al. Tibolone and risk of endometrial polyps: a prospective, comparative study with hormone therapy. Menopause. 2003;10(6):534-537.

11. Bueloni-Dias FN, Spadoto-Dias D, Delmanto LR, Nahas-Neto J, Nahas EA. Metabolic syndrome as a predictor of endometrial polyps in postmenopausal women. Menopause. 2016;23(7):759-764.

12. Daniele A, Ferrero A, Maggiorotto F, Perrini G, Volpi E, Sismondi P. Suspecting malignancy in endometrial polyps: value of hysteroscopy. Tumori. 2013;99(2):204-209.

13. NICE. 2007. Available from: https:/www.nice.org.uk/guidance/ CG44/chapter/Recommendations-pharmaceutical-treatments-for-hmb. Accessed February, 01, 2017.

14. Royal College of Obstetricians and Gynaecologists. 2011. Available from: https://www.rcog.org.uk/globalassets/documents/guidelines/ gtg59hysteroscopy.pdf. Accessed February 27, 2017.

15. Morgan M, Dodds W, Wolfe C, Raju S. Women's views and experiences of outpatient hysteroscopy: implications for a patient-centered service. Nurs Health Sci. 2004;6(4):315-320.

16. Gupta JK, Clark TJ, More S, Pattison H. Patient anxiety and experiences associated with an outpatient "one-stop" "see and treat" hysteroscopy clinic. Surg Endosc. 2004;18(7):1099-1104.

17. Munro MG, Heikinheimo O, Haththotuwa R, Tank JD, Fraser IS. The need for investigations to elucidate causes and effects of abnormal uterine bleeding. Semin Reprod Med. 2011;29(5):410-422.

18. Batzer FR. Abnormal uterine bleeding: imaging techniques for evaluation of the uterine cavity and endometrium before minimally invasive surgery - the case for transvaginal ultrasonography. J Minim Invasive Gynecol. 2007;14(1):9-11.

19. Emanuel MH, Verdel MJ, Wamsteker K, Lammes FB. A prospective comparison of transvaginal ultrasonography and diagnostic hysteroscopy in the evaluation of patients with abnormal uterine bleeding: clinical implications. Am J Obstet Gynecol. 1995;172(2 pt 1):547-552.

20. Breitkopf DM, Frederickson RA, Snyder RR. Detection of benign endometrial masses by endometrial stripe measurement in premenopausal women. Obstet Gynecol. 2004;104(1):120-125.

21. Dueholm M, Lundorf E, Hansen ES, Ledertoug S, Olesen F. Evaluation of the uterine cavity with magnetic resonance imaging, transvaginal sonography, hysterosonographic examination, and diagnostic hysteroscopy. Fertil Steril. 2001;76(2):350-357.

22. Berridge DL, Winter TC. Saline infusion sonohysterography: technique, indications, and imaging findings. J Ultrasound Med. 2004;23(1): 97-112; quiz 114-115.

23. Farquhar C, Ekeroma A, Furness S, Arroll B. A systematic review of transvaginal ultrasonography, sonohysterography and hysteroscopy for the investigation of abnormal uterine bleeding in premenopausal women. Acta Obstet Gynecol Scand. 2003;82(6):493-504.

24. Grimbizis GF, Tsolakidis D, Mikos T, et al. A prospective comparison of transvaginal ultrasound, saline infusion sonohysterography, and diagnostic hysteroscopy in the evaluation of endometrial pathology. Fertil Steril. 2010;94(7):2720-2725.

25. Yildizhan B, Yildizhan R, Ozkesici B, Suer N. Transvaginal ultrasonography and saline infusion sonohysterography for the detection of intra-uterine lesions in pre- and post-menopausal women with abnormal uterine bleeding. J Int Med Res. 2008;36(6):1205-1213.

26. Short J, Sharp B, Elliot N, et al. Does the addition of saline infusion sonohysterography to transvaginal ultrasonography prevent unnecessary hysteroscopy in premenopausal women with abnormal uterine bleeding? Aust N Z J Obstet Gynaecol. 2016;56(4):432-435.

27. Dueholm M, Lundorf E, Hansen ES, Ledertoug S, Olesen F. Accuracy of magnetic resonance imaging and transvaginal ultrasonography in the diagnosis, mapping, and measurement of uterine myomas. Am J Obstet Gynecol. 2002;186(3):409-415.

28. Bettocchi S, Ceci O, Vicino M, Marello F, Impedovo L, Selvaggi L. Diagnostic inadequacy of dilatation and curettage. Fertil Steril. 2001; 75(4):803-805.

29. Dijkhuizen FP, Mol BW, Brolmann HA, Heintz AP. The accuracy of endometrial sampling in the diagnosis of patients with endometrial carcinoma and hyperplasia: a meta-analysis. Cancer. 2000;89(8):1765-1772. 
30. Angioni S, Loddo A, Milano F, Piras B, Minerba L, Melis GB. Detection of benign intracavitary lesions in postmenopausal women with abnormal uterine bleeding: a prospective comparative study on outpatient hysteroscopy and blind biopsy. J Minim Invasive Gynecol. 2008;15(1):87-91.

31. Bettocchi S, Selvaggi L. A vaginoscopic approach to reduce the pain of office hysteroscopy. J Am Assoc Gynecol Laparosc. 1997;4(2): 255-258.

32. Ben-Arie A, Goldchmit C, Laviv Y, et al. The malignant potential of endometrial polyps. Eur J Obstet Gynecol Reprod Biol. 2004;115(2): 206-210.

33. van Dongen $\mathrm{H}$, de Kroon CD, Jacobi CE, Trimbos JB, Jansen FW. Diagnostic hysteroscopy in abnormal uterine bleeding: a systematic review and meta-analysis. BJOG. 2007;114(6):664-675.

34. O'Flynn H, Murphy LL, Ahmad G, Watson AJ. Pain relief in outpatient hysteroscopy: a survey of current UK clinical practice. Eur J Obstet Gynecol Reprod Biol. 2011;154(1):9-15.

35. De Iaco P, Marabini A, Stefanetti M, Del Vecchio C, Bovicelli L. Acceptability and pain of outpatient hysteroscopy. J Am Assoc Gynecol Laparosc. 2000;7(1):71-75.

36. Jansen FW, Vredevoogd CB, van Ulzen K, Hermans J, Trimbos JB, Trimbos-Kemper TC. Complications of hysteroscopy: a prospective, multicenter study. Obstet Gynecol. 2000;96(2):266-270.

37. Stankova T, Ganovska A, Stoianova M, Kovachev S. [Complications of diagnostic and operative hysteroscopy - review]. Akush Ginekol. 2015;54(8):21-27.

38. McGurgan PM, McIlwaine P. Complications of hysteroscopy and how to avoid them. Best Pract Res Clin Obstet Gynaecol. 2015;29(7): 982-993.

39. Kayatas S, Meseci E, Tosun OA, Arinkan SA, Uygur L, Api M. Experience of hysteroscopy indications and complications in 5,474 cases. Clin Exp Obstet Gynecol. 2014;41(4):451-454.

40. Bradley LD. Diagnosis of abnormal uterine bleeding with biopsy or hysteroscopy. Menopause. 2011;18(4):425-433.

41. Clark TJ. Outpatient hysteroscopy and ultrasonography in the management of endometrial disease. Curr Opin Obstet Gynecol. 2004; 16(4):305-311.

42. Soguktas S, Cogendez E, Kayatas SE, Asoglu MR, Selcuk S, Ertekin A. Comparison of saline infusion sonohysterography and hysteroscopy in diagnosis of premenopausal women with abnormal uterine bleeding. Eur J Obstet Gynecol Reprod Biol. 2012;161(1):66-70.

43. Cooper NA, Barton PM, Breijer M, et al. Cost-effectiveness of diagnostic strategies for the management of abnormal uterine bleeding (heavy menstrual bleeding and post-menopausal bleeding): a decision analysis. Health Technol Assess. 2014;18(24):1-201, v-vi.

44. Nathani F, Clark TJ. Uterine polypectomy in the management of abnormal uterine bleeding: a systematic review. J Minim Invasive Gynecol. 2006;13(4):260-268.

45. van Dongen H, Janssen CA, Smeets MJ, Emanuel MH, Jansen FW. The clinical relevance of hysteroscopic polypectomy in premenopausal women with abnormal uterine bleeding. BJOG. 2009;116(10): $1387-1390$
46. Cicinelli E. Hysteroscopy without anesthesia: review of recent literature. J Minim Invasive Gynecol. 2010;17(6):703-708.

47. Marwah V, Bhandari SK. Diagnostic and interventional microhysteroscopy with use of the coaxial bipolar electrode system. Fertil Steril. 2003;79(2):413-417.

48. Cooper NA, Clark TJ, Middleton L, et al. Outpatient versus inpatient uterine polyp treatment for abnormal uterine bleeding: randomised controlled non-inferiority study. BMJ. 2015;350:h1398.

49. Cicinelli E, Tinelli R, Loiudice L, et al. AlphaScope vs lens-based hysteroscope for office polypectomy without anesthesia: randomized controlled study. J Minim Invasive Gynecol. 2011;18(6):796-799.

50. Garuti G, Centinaio G, Luerti M. Outpatient hysteroscopic polypectomy in postmenopausal women: a comparison between mechanical and electrosurgical resection. J Minim Invasive Gynecol. 2008;15(5): 595-600.

51. Diwakar L, Roberts TE, Cooper NA, et al. An economic evaluation of outpatient versus inpatient polyp treatment for abnormal uterine bleeding. BJOG. 2016;123(4):625-631.

52. Smith PP, Middleton LJ, Connor M, Clark TJ. Hysteroscopic morcellation compared with electrical resection of endometrial polyps: a randomized controlled trial. Obstet Gynecol. 2014;123(4):745-751.

53. Karamanidis D, Nicolaou P, Byros A, Koutsougeras G. Two-year results of a new two-minute hot liquid balloon endometrial ablation system (Thermablate): a pilot study. Clin Exp Obstet Gynecol. 2009; 36(4):256-258

54. Kalkat RK, Cartmill RS. NovaSure endometrial ablation under local anaesthesia in an outpatient setting: an observational study. J Obstet Gynaecol. 2011;31(2):152-155

55. Thakur Y, Thakur V, Gupta N, Rathod K, Karunaratne C. Minitouch outpatient endometrial ablation procedure. J Minim Invasive Gynecol. 2015;22(6S):S183.

56. Lethaby A, Hickey M, Garry R, Penninx J. Endometrial resection/ ablation techniques for heavy menstrual bleeding. Cochrane Database Syst Rev. 2009;4:CD001501.

57. Middleton LJ, Champaneria R, Daniels JP, et al. Hysterectomy, endometrial destruction, and levonorgestrel releasing intrauterine system (Mirena) for heavy menstrual bleeding: systematic review and metaanalysis of data from individual patients. BMJ. 2010;341:c3929.

58. Clark TJ, Mahajan D, Sunder P, Gupta JK. Hysteroscopic treatment of symptomatic submucous fibroids using a bipolar intrauterine system: a feasibility study. Eur J Obstet Gynecol Reprod Biol. 2002; 100(2):237-242.

59. de Wit AC, Vleugels MP, de Kruif JH. Diagnostic hysteroscopy: a valuable diagnostic tool in the diagnosis of structural intra-cavital pathology and endometrial hyperplasia or carcinoma? Six years of experience with non-clinical diagnostic hysteroscopy. Eur J Obstet Gynecol Reprod Biol. 2003;110(1):79-82.

60. Kolhe S. Setting up of ambulatory hysteroscopy service. Best Practices Res Clin Obstet Gynaecology. 2015;29(7):966-981.
International Journal of Women's Health

\section{Publish your work in this journal}

The International Journal of Women's Health is an international, peerreviewed open-access journal publishing original research, reports, editorials, reviews and commentaries on all aspects of women's healthcare including gynecology, obstetrics, and breast cancer. The manuscript management system is completely online and includes

\section{Dovepress}

a very quick and fair peer-review system, which is all easy to use Visit http://www.dovepress.com/testimonials.php to read real quotes from published authors. 